\title{
PERFORMANCE TEST AND OPERATING CONDITION OPTIMIZATION OF PARALLEL PLATE PLASMA REACTOR FOR CARBON DIOXIDE DECOMPOSITION
}

\author{
Renno Afriansyah ${ }^{1}$, Sheila Nadhifa ${ }^{1}$, Setijo Bismo ${ }^{1 *}$ \\ ${ }^{1}$ Department of Chemical Engineering, Faculty of Engineering, Universitas Indonesia., \\ Kampus UI Depok, Depok 16424, Indonesia
}

(Received: March 2018 / Revised: June 2018 / Accepted: October 2018)

\begin{abstract}
A dielectric barrier discharge (DBD) plasma reactor for carbon dioxide $\left(\mathrm{CO}_{2}\right)$ decomposition was developed to address the current phenomena of $\mathrm{CO}_{2}$ emissions exceeding $400 \mathrm{ppm}$ in the atmosphere. As is widely known, $\mathrm{CO}_{2}$ is one of the main causes of global warming and climate change. In this research, a parallel plate plasma reactor was designed by modifying the DBD reactor configured with two parallel electrodes. The casing of the reactor was modified using an acrylic plate that acts as a shell for the optimal contact between the $\mathrm{CO}_{2}$ gas and the electrodes. The DBD reactor uses a $220 \mathrm{VAC}$ line power (PLN), 50-60 Hz frequency. The performance of the DBD reactor was tested and optimized by varying the regulator output (AC) voltage and the $\mathrm{CO}_{2}$ feed flow rate to obtain the optimal operating conditions from the parallel plate plasma reactor for decomposition of $\mathrm{CO}_{2}$. The optimal process performance for the 7-gram (ozone production equivalent) plasma reactor was achieved at a discharge power of $82 \mathrm{Watts}$ and a feed flow rate of $1.2 \mathrm{~L} \cdot \mathrm{min}^{-1}$ with $\mathrm{CO}_{2}$ conversion of $4.413 \%$ and energy efficiency of $2.093 \times 10^{-3}$ mol. $\mathrm{J}^{-1}$. The optimal process performance for the 10-gram (ozone production equivalent) plasma reactor was achieved at a discharge power of $74 \mathrm{Watta}$ and a feed flow rate of $1.2 \mathrm{~L}^{-\mathrm{min}^{-1}}$ with $\mathrm{CO}_{2}$ conversion of $3.949 \%$ and energy efficiency of $2.074 \times 10^{-3} \mathrm{~mol}^{-\mathrm{J}^{-1}}$.
\end{abstract}

Keywords: Carbon dioxide decomposition; Dielectric barrier discharge; Non-thermal plasma reactor; Operating condition; Parallel plate

\section{INTRODUCTION}

The use of fossil fuels is increasing. It is known that carbon dioxide $\left(\mathrm{CO}_{2}\right)$ gas is the result of fossil fuel combustion, and $\mathrm{CO}_{2}$ is one of the main causes of global warming and climate change. In 2013, $\mathrm{CO}_{2}$ the emissions levels exceeded $400 \mathrm{ppm}$, which is the threshold of atmospheric $\mathrm{CO}_{2}$ content. If the burning of fossil fuels continues at the same level, the $\mathrm{CO}_{2}$ content in the atmosphere will continue to increase to the level of $1500 \mathrm{ppm}$. This increase in $\mathrm{CO}_{2}$ levels have been shown to have a very constant relationship with the burning of fossil fuels, and it can be calculated on the simple estimate that about $60 \%$ of fossil fuel emissions remain in the air (NASA, 2018). Significant efforts have been made to develop several technologies to overcome the role of $\mathrm{CO}_{2}$ in causing global warming by utilizing $\mathrm{CO}_{2}$ as a raw material to produce valuable fuels and chemicals, such as carbon monoxide (CO), dihydrogen $\left(\mathrm{H}_{2}\right)$, and methanol (Mei et al., 2015). In a non-thermal plasma reactor, the decomposition of $\mathrm{CO}_{2}$ results in the formation of $\mathrm{CO}$ gas, which has some benefit as a raw material for methanol manufacture and as reducing agent in iron

\footnotetext{
${ }^{*}$ Corresponding author's email: setijo.bismo@ui.ac.id, Tel: +62-21-7863516, Fax: +62-21-7863515 Permalink/DOI: https://doi.org/10.14716/ijtech.v9i6.2363
} 
processing. Utilization of $\mathrm{CO}_{2}$ has a significant positive impact on producing a more valuable product, and it helps reduce the negative impact of carbon emissions on the environment. However, considerable energy and cost is required to decompose $\mathrm{CO}_{2}$ because the molecules have high stability (Mei et al., 2015). Decomposition of $\mathrm{CO}_{2}$ into $\mathrm{CO}$ is an endothermic reaction, as shown in Equation 1 (Mei et al., 2015):

$$
\mathrm{CO}_{2} \rightleftharpoons \mathrm{CO}+\frac{1}{2} \mathrm{O}_{2} \quad \Delta \mathrm{H}=280 \mathrm{~kJ} \cdot \mathrm{mol}^{-1}
$$

Non-thermal plasma technology is one type of alternative technology that can be used to decompose $\mathrm{CO}_{2}$ into valuable fuels and chemicals. This technology operates at atmospheric pressure and room temperature so the non-equilibrium characteristics require relatively less energy than other methods. Several types of plasma reactors have been developed for $\mathrm{CO}_{2}$ conversion, such as dielectric barrier discharge (DBD), corona discharge (CD), glow discharge (GD), microwave discharge, radio frequency discharge, and gliding arc discharge (Mei et al., 2015). However, previous research using various types of reactors has focused more on plasma conversion of $\mathrm{CO}_{2}$ diluted with inert gases, such as helium and argon, which are unfavorable for industrial applications due to their high cost (Mei et al., 2015).

The decomposition of $\mathrm{CO}_{2}$ into $\mathrm{CO}$ and oxygen $\left(\mathrm{O}_{2}\right)$ by non-thermal plasma reactors has attracted significant attention because it is almost impossible for a reaction to occur at low temperatures using a conventional catalysis (Ashford \& Tu, 2016). As one of the greenhouse gas emissions, $\mathrm{CO}_{2}$ can be decomposed into $\mathrm{CO}$ and $\mathrm{O}_{2}$ in a three-pass-flow DBD reactor, a reactor designed so that the gas stream of the reaction has a special configuration. This configuration can simultaneously cool the high voltage electrode (HVE) during the reaction process and preheat the gas feed stream before entering the plasma zone (Winanti et al., 2013).

The work prefix of DBD is an electrical firing between two electrodes separated by a dielectric insulation barrier. Also called a silent discharge, DBD is known as an ozone-producing device. This process uses high-voltage electrical charges. DBD reactors can be made in various configurations. Generally, these reactors are made in planar form using parallel plates separated by a dielectric material (Masruroh et al., 2017; Istadi, 2006). Moreover, a DBD reactor can also be made in a cylindrical shape using a wire-shaped plate with a dielectric pipe between the two electrodes.

In plasma reactors, high-energy electrons collide with the gas molecules to produce excitation and ionization, and to form atoms and metastable compounds. If the electric field within the discharge zone is sufficient to break the chemical bond of the gas, it will show a large number of micro-discharges. Furthermore, the active atoms and metastable compounds will collide with the molecules resulting in a chemical reaction. The collision between the high-energy electrons and gas molecules results in excitation, dissociation, or ionization without causing the gas to heat, so the gas bulk temperature is always low and differs from the temperature of the electrons. Excitation of this gas creates a phenomenon that marks the formation of plasma, the emission of light in the visible light spectrum (Istadi, 2006).

Conversion of $\mathrm{CO}_{2}$ plasma is a complex and challenging process that involves a large number of physical and chemical reactions. The reaction performance, such as $\mathrm{CO}_{2}$ conversion and the energy efficiency of this process, is strictly controlled by various plasma process parameters, such as the discharge power, gas flow rate, gas residence time, and reactor configuration. This is often a major concern when exploring the relationship between the independent key input variables and output performance characteristics of plasma processes (Istadi, 2006). 
DBD reactors have been developed for decomposition of $\mathrm{CO}_{2}$ at atmospheric pressure. The optimization methodology is based on three factors: discharge power, feed flowrate, and discharge distance. The Box-Behnken three-level design has been developed to determine the effect of independent key process parameters (discharge power, feed flow rate, discharge length) and their interaction with the reaction performance in terms of $\mathrm{CO}_{2}$ conversion and plasma process energy efficiency. The results show that $\mathrm{CO}_{2}$ conversion increases with increasing discharge power and discharge length, but it decreases with increasing feedback. When viewed from the effects of these parameters, discharge power is the most important factor affecting $\mathrm{CO}_{2}$ conversion, while feed flow rate has the most significant impact on process energy efficiency (Mei et al., 2015).

In this present research study, a parallel plate DBD reactor was developed for the $\mathrm{CO}_{2}$ decomposition reaction. A parallel plate DBD reactor has parallel ceramic (silica) plates that serve as dielectric material using acrylic as a shell (jacket material) to ensure that the reaction between the gas and electrodes is optimal. This study also tested some parameters, such as discharge power and feed flow rate, to determine the optimal operating conditions.

\section{METHODS}

The experiment was carried out in a parallel plate DBD plasma reactor. The parallel plate plasma reactor was designed by modifying the ozonator device, which has a configuration of two similar parallel electrodes.

\subsection{Experimental Setup}

This experiment used two different types of ozonator specifications. The first ozonator has the ability to produce as much as 7 grams of ozone per hour; it has electrodes with a length of $8.5 \mathrm{~cm}$ and a width of $5 \mathrm{~cm}$. The second ozonator has the ability to produce as much as 10 grams of ozone per hour; it has electrodes with a length of $10 \mathrm{~cm}$ and a width of $5 \mathrm{~cm}$. The ozonators are modified by installing acrylic as a shell that acts to trap the $\mathrm{CO}_{2}$ gas so a reaction can occur between the gas and the electrodes. The installed shell has a beam-shaped length of $18.5 \mathrm{~cm}$, a width of $10 \mathrm{~cm}$, and a height of $12 \mathrm{~cm}$. On the inside of the box, the acrylic is installed as a barrier between the top and bottom portions of the reactor. The feed gas is drained from the bottom and the resultant gas is produced at the top. The design of the parallel plate plasma reactor is outlined in Figure 1.

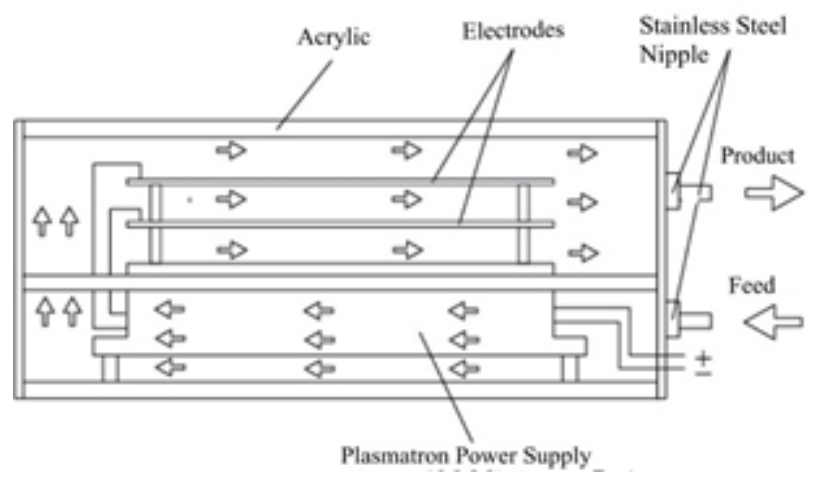

Figure 1 Parallel plate plasma reactor with a feed flow scheme

The reactor used a voltage of $220 \mathrm{VAC}$ and a frequency of $50 \mathrm{~Hz}$, which was sourced from a state power plant. A dimmer was used to adjust the voltage used by the reactor. A voltmeter was used to measure the voltage. A multimeter was used to measure the discharge power used by the reactor. In this experiment, $\mathrm{CO}_{2}$ gas was used as the feed gas by passing it through the flow meter 
to adjust the feed flow rate. The feed gas flowed in from the bottom of the reactor and out from the top of it. The product gas was captured using a gas bag, and then the sample was tested qualitatively using a gas chromatograph (GC). Figure 2 shows a schematic diagram of the experimental setup.

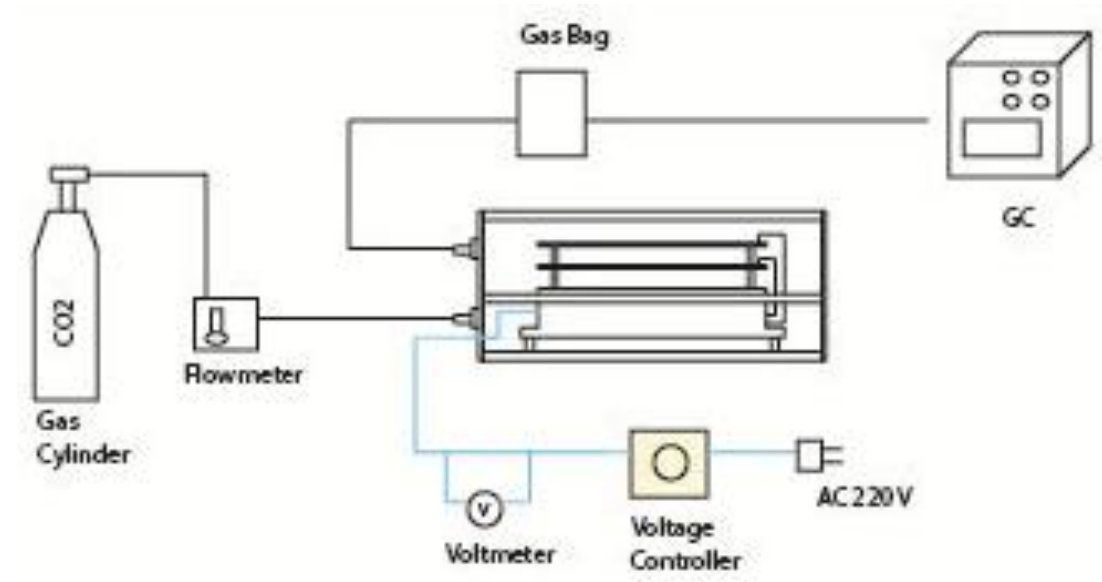

Figure 2 Schematic diagram of the experimental setup

\subsection{Product Analysis}

The feed and product gases were analyzed using GC equipped with a thermal conductivity detector (TCD). The resulting data were used to calculate $\mathrm{CO}_{2}$ conversion (C) and energy consumption (E). The following equations were used to calculate both values (Mei et al., 2015):

$$
\begin{gathered}
\mathrm{C}_{\mathrm{CO}_{2}}(\%)=\frac{\left.\mathrm{C}_{\mathrm{CO}_{2}} \text { converted (mol.s }{ }^{-1}\right)}{\mathrm{C}_{\mathrm{CO}_{2}} \text { introduced }\left(\text { mol.s }^{-1}\right)} \times 100 \% \\
E\left(\text { mol. } \mathrm{J}^{-1}\right)=\frac{\left.\mathrm{C}_{\mathrm{CO}_{2} \text { converted }(\text { mol.s }}{ }^{-1}\right)}{\text { Discharged power }(\text { Watt })}
\end{gathered}
$$

\section{RESULTS AND DISCUSSION}

In this experiment, $\mathrm{CO}$ and $\mathrm{O}_{2}$ were the two gas products obtained from the plasma conversion of pure $\mathrm{CO}_{2}$. This paper mainly focuses on the effect of different processing parameters on $\mathrm{CO}_{2}$ conversion and energy efficiency and the optimization of these parameters to provide valuable information for the development of a cost-effective plasma process for $\mathrm{CO}_{2}$ conversion.

\subsection{Effect of the Plasma Process Parameters on $\mathrm{CO}_{2}$ Conversion}

The effect of the flow rate on the $\mathrm{CO}_{2}$ conversion is shown in the graph in Figure 3. This flow rate experiment was performed at 220 VAC. As seen in Figure 3, decreasing the $\mathrm{CO}_{2}$ flow rate increases the $\mathrm{CO}_{2}$ conversion. This occurs because when the flow rate decreases, the residence time of the reactant inside the reactor increases, thereby increasing the chance for the $\mathrm{CO}_{2}$ molecules to react with the energetic electrons and reactive species.

When the flow rate of the two types of reactors were varied, the same effect was observed. The largest conversion of the two reactors is at a flow rate of $0.3 \mathrm{~L} / \mathrm{min}$. The 7 -gram reactor has a $\mathrm{CO}_{2}$ conversion of $6.959 \%$ and the 10-gram reactor has a $\mathrm{CO}_{2}$ conversion of $6.050 \%$. The $\mathrm{CO}_{2}$ conversion is larger for the 7 -gram reactor than the 10-gram reactor because, at the same voltage, the 7-gram reactor has a greater discharge power than the 10-gram reactor. The effect of the discharge power is shown in the graph in Figure 4. The discharge power experiments were carried 
out at a flow rate of $0.9 \mathrm{~L} / \mathrm{min}$. The discharge power variations were done by changing the voltage values.

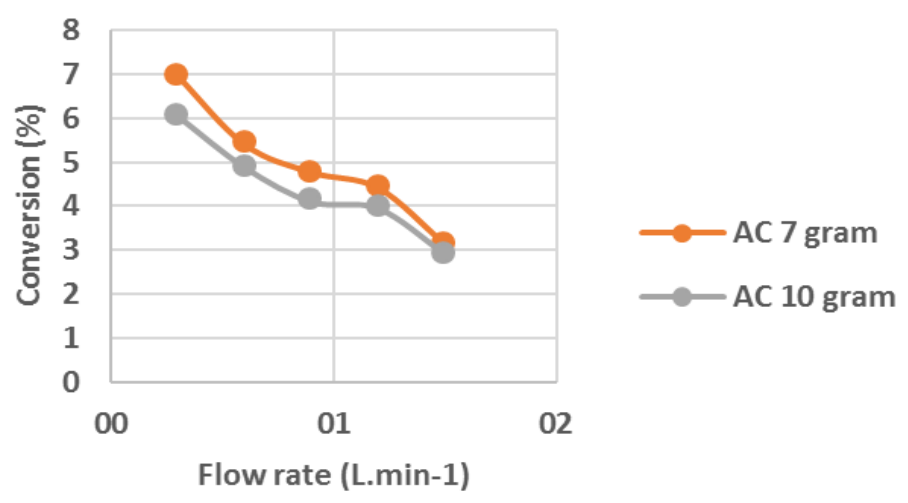

Figure 3 Effect of the feed flow rate on the $\mathrm{CO}_{2}$ conversion

The Figure 4 shows that, in terms of discharge power, the greater the voltage used the greater the $\mathrm{CO}_{2}$ conversion will be. The highest conversion of the two reactors occurred at a current of 220 VAC. The 7-gram reactor had a $\mathrm{CO}_{2}$ conversion of $4.765 \%$ and the 10 -gram reactor had a $\mathrm{CO}_{2}$ conversion of $3.946 \%$. This occurred because the number of micro-discharges and the current intensity in the $\mathrm{CO}_{2} \mathrm{DBD}$ increase as the discharge power or applied voltage increase, which can be observed from the increased number and amplitude of the current pulses in the electrical signal (Mei et al., 2015). Liu (2001) and succeeded by Ouyang et al. (2012), both also reported that the number of filaments per unit dielectric surface in a DBD reactor increases as the applied voltage increases. The increased number of micro-discharges in the $\mathrm{CO}_{2} \mathrm{DBD}$ suggests the formation of more reaction channels and electrons in the plasma, both of which contribute to the enhancement of the reaction performance (e.g., $\mathrm{CO}_{2}$ conversion) when increasing the discharge power of the $\mathrm{CO}_{2} \mathrm{DBD}$.

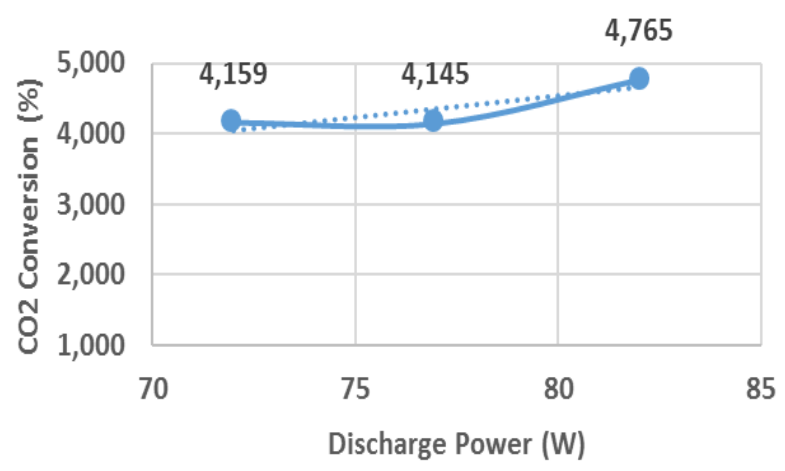

(a)

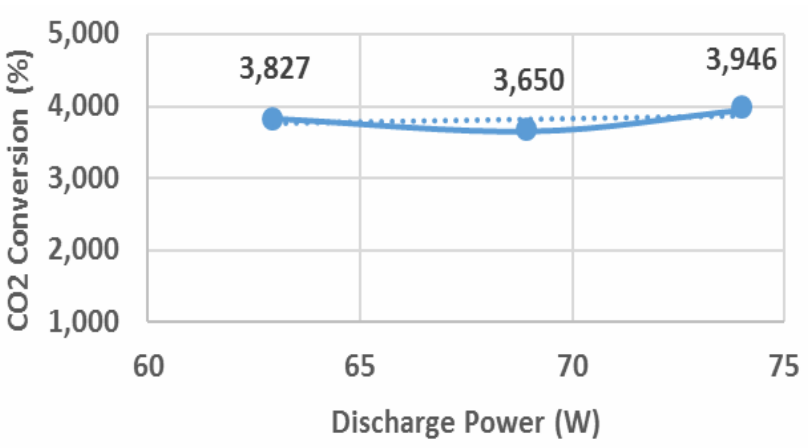

(b)

Figure 4 Effect of the power discharge on $\mathrm{CO}_{2}$ conversion: (a) 7-gram reactor; (b) 10-gram reactor

\subsection{Effect of Plasma Process Parameters on Energy Efficiency}

The flow rate's effect on energy efficiency is shown in the graph in Figure 5. Increasing the $\mathrm{CO}_{2}$ flow rate increases the energy efficiency. Decreasing the flow rate leads to an increase in the conversion, but the number of moles of converted $\mathrm{CO}_{2}$ also decrease. Thus, at the same discharge power, an increase in the flow rate leads to an increase in energy efficiency. The same effect was observed after varying the flow rate of the two types of reactor. The highest energy efficiency in the 7 -gram reactor at a flow rate of $1.2 \mathrm{~L} / \mathrm{min}$ was $0.00209 \mathrm{~mol} . \mathrm{J}^{-1}$; for the 10 -gram reactor at a flow rate of $1.2 \mathrm{~L} / \mathrm{min}$, the value was $0.00191 \mathrm{~mol}^{-1} \mathrm{~J}^{-1}$. The efficiency of the 7 -gram reactor decreased at the flow rate of $1.5 \mathrm{~L} / \mathrm{min}$ because the conversion at that flow rate is very small. 


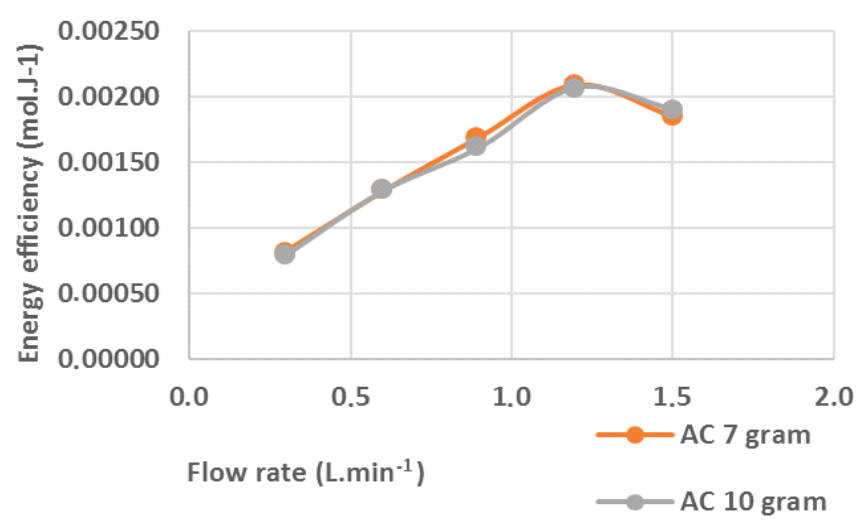

Figure 5 Effect of flow rate on energy efficiency

The effect of the discharge power on the energy efficiency is shown in the graph in Figure 6. The effect was different for both types of reactors. For the 7-gram reactor, a higher discharge power increased the energy efficiency, although the increase was not significant. For the 10-gram reactor, a higher discharge power decreased the energy efficiency because the increase in discharge power was not followed by a significant increase in the conversion value. The highest energy efficiency of the 7 -gram reactor at $220 \mathrm{VAC}$ was $0.0471 \mathrm{~mol}^{-\mathrm{J}^{-1}}$. The highest energy efficiency of the 10 -gram reactor at $180 \mathrm{VAC}$ was $0.0493 \mathrm{mol. \textrm {J } ^ { - 1 }}$.

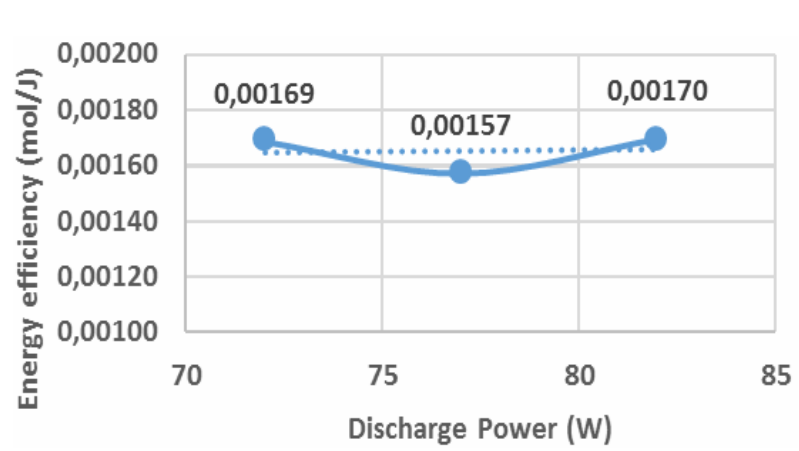

(a)

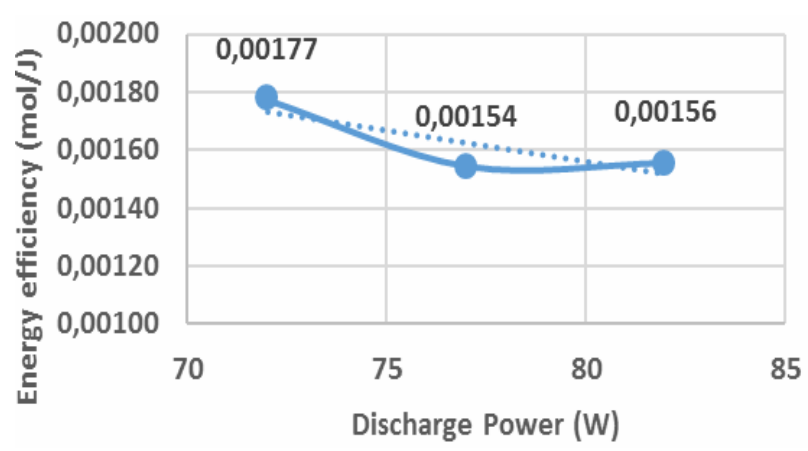

(b)

Figure 6 Effect of discharge power on energy efficiency: (a) 7-gram reactor; (b) 10-gram reactor

\subsection{Process Optimization}

The results of this study show that the $\mathrm{CO}_{2}$ conversion and energy efficiency of the plasma process cannot reach the maximum values simultaneously under the same plasma operating conditions. Increasing the discharge power will increase the conversion, but it will lead to decreased efficiency. However, increasing the discharge power and $\mathrm{CO}_{2}$ flow rate has an opposite effect on the $\mathrm{CO}_{2}$ conversion and energy efficiency (Aerts et al., 2015; Lebouvier et al., 2013). For example, a higher discharge power results in a higher $\mathrm{CO}_{2}$ conversion, but it decreases the energy efficiency of the process at a fixed $\mathrm{CO}_{2}$ flow rate. In contrast, a higher reactant flow leads to higher plasma process energy efficiency, but it significantly decreases the conversion of $\mathrm{CO}_{2}$.

Therefore, a balance between $\mathrm{CO}_{2}$ conversion and energy efficiency is significantly important for the development of an efficient plasma process for $\mathrm{CO}_{2}$ conversion. The overall performance of the plasma conversion of $\mathrm{CO}_{2}$ strongly depends on a wide range of plasma operating conditions. It is essential to optimize the plasma $\mathrm{CO}_{2}$ conversion process with multiple inputs and multiple responses. A global desirability function (D) has been introduced as a key parameter to identify the optimal processing parameters and performance in the plasma conversion of $\mathrm{CO}_{2}$. This 
function can be calculated from the product of the individual desirability function (di) for each response, as shown in the following equation:

$$
D=\left(d_{1} \times d_{2} \times \ldots \times d_{n}\right)^{\frac{1}{n}}
$$

where $n$ is the number of the responses in the experiment ( $\mathrm{n}=2$ in this work). The optimal process and processing parameters can be achieved when the highest value for $\mathrm{D}$ is found. The $\mathrm{D}$ calculation results for the 7-gram reactor and the 10-gram reactor are shown in Table 1 and Table 2 , respectively.

Table 1 Results of the global desirability calculation for the 7-gram reactor

\begin{tabular}{ccccc}
\hline $\begin{array}{c}\text { Discharge } \\
\text { power }(\mathrm{W})\end{array}$ & $\begin{array}{c}\text { Flow rate } \\
\left(\mathrm{L} . \mathrm{min}^{-1}\right)\end{array}$ & $\begin{array}{c}\mathrm{CO}_{2} \text { Conversion } \\
(\%)\end{array}$ & $\begin{array}{c}\text { Energy efficiency } \\
\left(\mathrm{mol.J}^{-1}\right) \times 10^{4}\end{array}$ & $\begin{array}{c}\text { Global desirability } \\
\times 10^{2}\end{array}$ \\
\hline 82 & 0.3 & 6.959 & 8.253 & 7.578 \\
82 & 0.6 & 5.401 & 12.81 & 8.319 \\
82 & 0.9 & 4.765 & 16.96 & 8.989 \\
82 & 1.2 & 4.413 & 20.93 & 9.612 \\
82 & 1.5 & 3.126 & 18.54 & 7.612 \\
77 & 0.9 & 4.159 & 15.76 & 8.095 \\
72 & 0.9 & 4.145 & 16.80 & 8.344 \\
77 & 1.2 & 3.640 & 18.39 & 8.182 \\
72 & 1.2 & 3.507 & 18.95 & 8.151 \\
\hline
\end{tabular}

Table 2 Results of the global desirability calculation for the 10-gram reactor

\begin{tabular}{ccccc}
\hline $\begin{array}{c}\text { Discharge } \\
\text { power }(\mathrm{W})\end{array}$ & $\begin{array}{c}\text { Flow rate } \\
\left(\text { L.min }^{-1}\right)\end{array}$ & $\begin{array}{c}\mathrm{CO}_{2} \text { Conversion } \\
(\%)\end{array}$ & $\begin{array}{c}\text { Energy efficiency } \\
\left(\text { mol.J }^{-1}\right) \times 10^{4}\end{array}$ & $\begin{array}{c}\text { Global } \\
\text { desirability } \times 10^{2}\end{array}$ \\
\hline 74 & 0.3 & 6.050 & 7.951 & 6.935 \\
74 & 0.6 & 4.879 & 12.82 & 7.910 \\
74 & 0.9 & 4.097 & 16.15 & 8.135 \\
74 & 1.2 & 3.946 & 20.74 & 9.047 \\
74 & 1.5 & 2.904 & 19.08 & 7.443 \\
69 & 0.9 & 3.965 & 16.77 & 8.135 \\
63 & 0.9 & 3.827 & 17.72 & 8.153 \\
69 & 1.2 & 3.650 & 20.58 & 8.236 \\
63 & 1.2 & 3.579 & 22.10 & 8.668 \\
\hline
\end{tabular}

As seen in Table 1, the optimal process performance for the 7-gram reactor was achieved at a discharge power of $82 \mathrm{~W}$ and a feed flow rate of $1.2 \mathrm{~L} \cdot \mathrm{min}^{-1}$ with $\mathrm{CO}_{2}$ conversion of $4.413 \%$ and an energy efficiency of $2.093 \times 10^{-3} \mathrm{mol.J} \mathrm{J}^{-1}$. As seen in Table 2, the optimal process performance for the 10-gram reactor was achieved at a discharge power of $74 \mathrm{~W}$ and a feed flow rate of 1.2 L. $\mathrm{min}^{-1}$ with a $\mathrm{CO}_{2}$ conversion of $3.949 \%$ and an energy efficiency of $2.074 \times 10^{-3} \mathrm{~mol}^{-\mathrm{J}^{-1}}$. 


\section{CONCLUSION}

This study investigated the effects of the key plasma process parameters (discharge power and feed flow rate) and their interactions on the plasma conversion of $\mathrm{CO}_{2}$ in a parallel plate plasma reactor. The results show that the conversion of $\mathrm{CO}_{2}$ increases with increasing discharge power, but it decreases as the feed flow rate increases; moreover, the energy efficiency increases as the $\mathrm{CO}_{2}$ flow rate increases, but it decreases as the discharge power increases. The optimal process performance of the 7-gram reactor was achieved at a discharge power of $82 \mathrm{~W}$ and a feed flow rate of $1.2{\mathrm{~L} . \mathrm{min}^{-1}}^{-1}$ with a $\mathrm{CO}_{2}$ conversion of $4.413 \%$ and an energy efficiency of $2.093 \times 10^{-3} \mathrm{~mol}^{-\mathrm{J}^{-}}$ ${ }^{1}$. The optimal process performance of the 10-gram reactor was achieved at a discharge power of $74 \mathrm{~W}$ and a feed flow rate of $1.2 \mathrm{~L} \cdot \mathrm{min}^{-1}$ with a $\mathrm{CO}_{2}$ conversion of $3.949 \%$ and an energy efficiency of $2.074 \times 10^{-3} \mathrm{~mol} . \mathrm{J}^{-1}$.

\section{ACKNOWLEDGEMENT}

This research was conducted thanks to a 2018 PITTA Grant (Hibah Publikasi Internasional Terindeks Tugas Akhir Mahasiswa Universitas Indonesia), which was organized by the Directorate of Research and Community Service (DRPM) - Universitas Indonesia. The authors state that there is no competing interest or conflict of financial interests.

\section{REFERENCES}

Aerts, R., Somers, W., Bogaerts, A., 2015. Carbon Dioxide Splitting in a Dielectric Barrier Discharge Plasma: A Combined Experimental and Computational Study. ChemSusChem, Volume 8(4), p. 702

Ashford, B., Tu, X., 2016. Non-Thermal Plasma Technology for the Conversion of $\mathrm{CO}_{2}$. Current Opinion in Green and Sustainable Chemistry, Volume 3, pp. 45-49

Winanti, W.S., Purwanto, W.W., Bismo, S., 2013. Decomposition of Carbon Dioxide in the Three-Pass Flow Dielectric Barrier Discharge Plasma Reactor. International Journal of Technology, Volume 5(1), pp. 1-11

Istadi, 2006. Aplikasi Teknologi Hibrid Katalisis Plasma dalam Pengembangan Reaktor Kimia Masa Depan (Application of Plasma Catalysis Hybrid Technology in the Development of Future Chemical Reactors). Bulletin of Chemical Reaction Engineering \& Catalysis, Volume 1(2), pp. 15-20

Lebouvier, A., Iwarere, S.A., d'Argenlieu, P., Ramjugernath, D., Fulcheri, L., 2013. Assessment of Carbon Dioxide Dissociation as a New Route for Syngas Production: A Comparative Review and Potential of Plasma-based Technologies. Energy \& Fuels, Volume 27(5), pp. $2712-2722$

Liu, C.J., 2001. Methane Conversion to Higher Hydrocarbons in the Presence of Carbon Dioxide using Dielectric-barrier Discharge Plasmas. Plasma Chemistry and Plasma Processing, Volume 21(3), pp. 301-310

Masruroh, M., Hanif, M.A., Sakti, S.P., Santjojo, D.D.H., 2017. Plasma Power Effect on the Surfaces of a Quartz Crystal during Etching using Tetrafluoroethane Gas. International Journal of Technology, Volume 8(8), pp. 1525-1532

Mei, D., He, Y., Liu, S., Yan, J., Tu, X., 2015. Optimization of $\mathrm{CO}_{2}$ Conversion in a Cylindrical Dielectric Barrier Discharge Reactor using Design of Experiments. Plasma Processes and Polymers, Volume 13, pp. 544-556

NASA, 2013. The Relentless Rise of Carbon Dioxide. Global Climate Change. Available online at https://climate.nasa.gov/climate_resources/24/graphic-the-relentless-rise-of-carbondioxide/, Accessed on April 24, 2018

Ouyang, J.T., Duan, X.X., Xu, S.W., He, F., 2012. The Key Factor for Uniform and Patterned Glow Dielectric Barrier Discharge. Chinese Physics Letters, Volume 29(2), pp. 1-4 